\title{
Optimization of reinforced concrete structures: importance of design detail level
}

\author{
Ashot Tamrazyan, and Anatoly Alekseytsev* \\ Moscow State University of Civil Engineering, Yaroslavskoe shosse, 26, Moscow, 129337, Russia
}

\begin{abstract}
The study of the influence for design solution detailing on the cost of reinforced concrete structures during their optimization is carried out. A hypothesis is formulated on the final improvement of the target criterion with an increase in the number of variable parameters. Depending on this number, the concepts of three levels of detail are introduced, at which optimization can be carried out, and the degree of risk of failure of the structure is indicated for them. Using the example of finding a constructive solution for a reinforced concrete beam by the cost minimization criterion, the relationship of the cost change is shown when the number of independently variable parameters changes. The normal operation of the beam and the emergency action effects in the form of local damage to a single corner connection are taken into account. Genetic algorithms are used for the optimization.
\end{abstract}

\section{Introduction}

The design of load-bearing building structures is associated with the fulfillment of design requirements and the implementation of unification. The same principles should be extended to modern techniques that implement the optimization of structures according to a given criterion. Currently, these goals are met by several groups of probabilistic methods, one of which is genetic algorithms [1-5], which allow you to effectively take into account the symmetry, unification and valid work of the structure $[6,7]$, perform the synthesis of topology $[8,9]$ and parameters [10-14].

The practice of using genetic algorithms has shown that problems with a fairly large number of variable parameters can be solved on their basis; however, with an increase in the number of these parameters, the convergence of the computational process towards the optimal solution deteriorates. At the same time, the actual design process is inevitably associated with an increase in the number of variable parameters, due to the ever-increasing complexity of design solutions. Therefore, the problem of rational unification comes to the fore, associated with the degree of detail of the design solution. For the unification of genetic algorithms, variable parameters are used, for which the values are taken according to a given relation [15-18], for example the same. It seems relevant to study the influence of an increase in the number of variable parameters (the degree of detail of a design solution) on the value of the target optimality criterion while ensuring the convergence of the

*Corresponding author: aalexw@mail.ru 
iterative process. Some aspects of this problem have been discussed in [23, 24]. At the same time, the selected details of the design solution should ensure both regulatory operational requirements and survivability conditions under emergency action. By influences this emergencies we mean the failure of key load bearing elements, supports or their parts caused by mechanical damage. In this article, this problem is solved by the example of a reinforced concrete beam, taking into account its normal operation, as well as in an emergency. The minimization of its cost is taken as a goal criterion.

\section{Formulation of the main hypothesis and method of problem solving}

Let us introduce the concept of parameter variation level, by which we mean the number of variable parameters $V$ specified by the designer for the same system in different implementations of the optimization algorithm. It is differentiate three of these levels: minimal design $(M L)$ original design $(D L)$ and research design $(R L)$ (see Fig. 1). By minimum level it is means the minimum rational number of variable parameters of the object. This is the level of traditional design in accordance with regulatory requirements. By original design level, it is means the number of variable parameters that meet the requirements of standardization, type assignment and unification in construction, as well as the requirements of symmetry, structural and technological characteristics of the installation. Research level - the maximum number of variable parameters, limited by the computing power and the capabilities of the search algorithms.
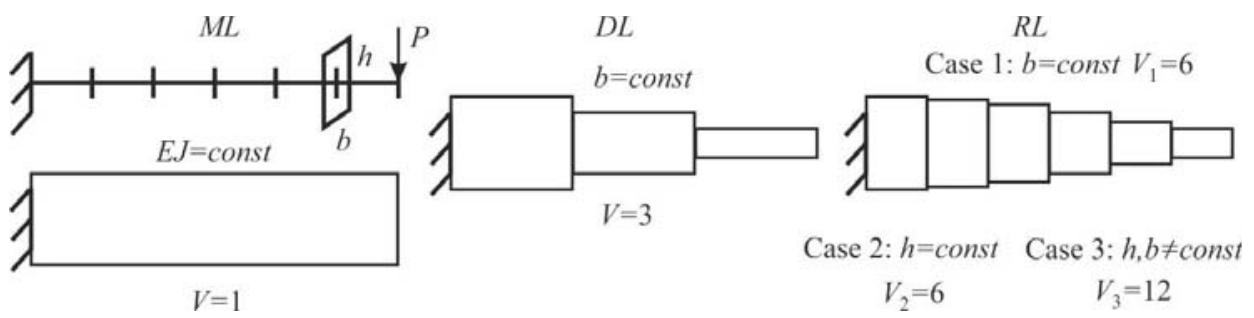

Fig. 1. Levels of detail for optimal design and number of variable parameters

Let us illustrate this concept by the example of the synthesis of a cantilever beam with varying cross-sectional dimensions. If we consider the relationship of these levels of detail with the external environment, then in order to increase the reliability of the system, must taking into account the period of its operation in time $t$. It is possible to make a decision on the level of detail of the variable parameters, taking into account also the margin $\xi_{0}$ of the operating resource (Fig. 2).

As any supporting structure has its own degree of resistance to the loss of its exploration performance, we introduce the concept of the risk level associated with this degree. It is defined the relative risk level for a structure as the ratio of the total volume of material losses to the expected cost of all supporting structures. For an individual load-bearing structure, the risk level is the ratio between the amount of property damage associated with the local destruction of part of the structure caused by the failure of the structure and the expected cost of the structure itself. At the same time, it becomes evident that the relative risk to key load-bearing elements of a structure without preventive measures to ensure survival in emergencies can be very high. 

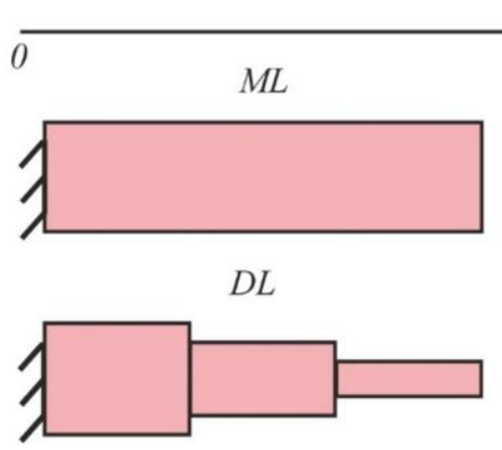

a)
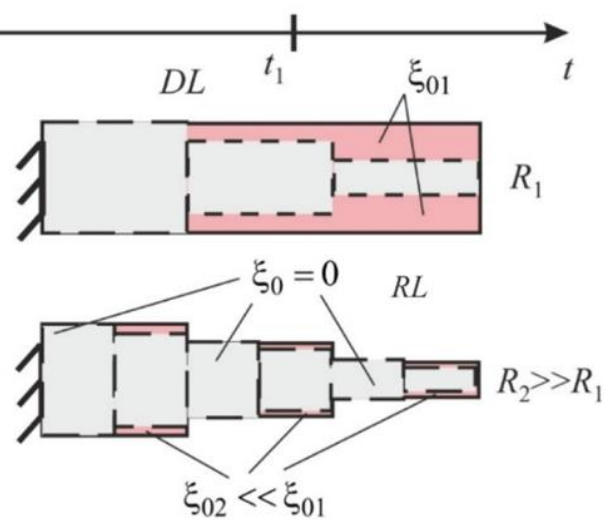

b)

Fig. 2. Risk assessment in case of degradation of optimal systems in time

Thus, we formulate the conjecture. The use of optimization methods to find the parameters and structures of buildings load-bearing systems and structures allows to obtain variants of design solutions with properties close to the global minimum in terms of resource intensity while ensuring the level of mechanical safety required. The number of variable parameters determines the size of the variants sets generated for the objects, the solution unification requirements and the degree of approximation of the overall optimum.

As part of the scientific and technical hypothesis advanced in the works, it seems necessary to establish the relationship between the cost of the optimized design solution and the degree of detail of the design solution, which is determined by the number of variable parameters.

To investigate the relationship between the optimal cost $C$ of the structure and the degree of design solution detail, using the example of a reinforced concrete beam structure, we pose the problem of finding the dependency

$$
C(\{Y\})=F(N) \text {, }
$$

where $N$ is a number of independently variable parameters, $\{Y\}-$ are sets of the variable parameters. Given the absence of an explicit form of this functional dependence, this task can be solved by decomposition into subtasks of the form

$$
C|N=1 \rightarrow \min , C| N=2 \rightarrow \min , \ldots, C \mid N=N_{\max } \rightarrow \min ,
$$

where $N_{\max }$ is the limiting number of independently variable parameters, determined by design and technological requirements, including the conditions for unification of symmetry, modular system of dimensions in construction.

Each of the optimization problems in expression (2) is solved with a unified system of constraints, including requirements for the limit states of the first and second groups, as well as requirements for ensuring structural safety in emergency situations. In this case, only mechanical safety is considered with the removing from their design diagram of the supporting parts of structural elements. The genetic algorithm described in [20] is adopted as a tool for finding a solution.

\section{Results}

Let us consider the solution of problem (1) in the form (2) using the example of a reinforced concrete beam without prestressing. The design diagram of the beam is shown in 
fig. 3, where the types of variable parameters are indicated, as well as parameters that remain constant during the search for a solution.

a)
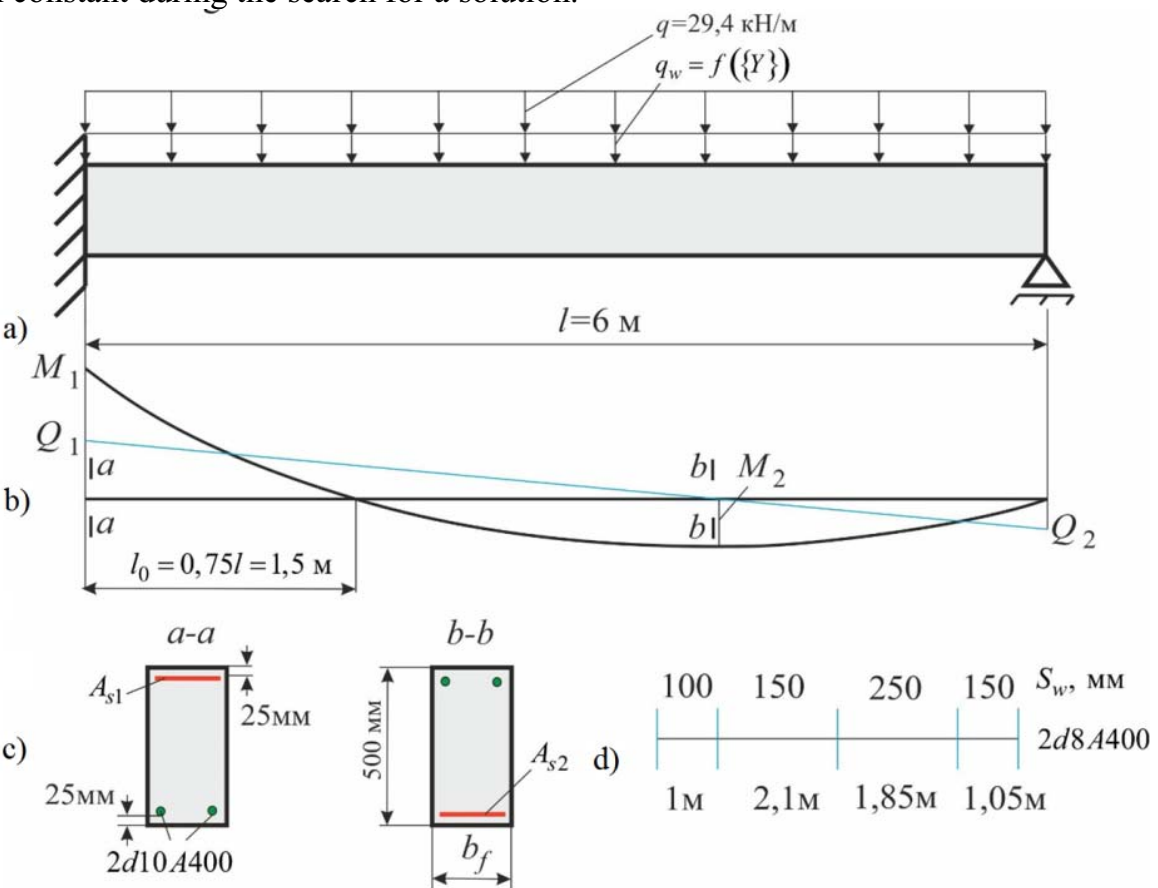

Fig. 3. Design diagram of a reinforced concrete beam: geometric diagram and loading (a), diagrams of internal forces (b), longitudinal reinforcement (c), transverse reinforcement (d)

It is believed that the beam is subject to its own weight load $q_{w}$, the intensity of which is determined by the state of the variable parameters represented in the form of a set $\{Y\}$, the size of which is equal $N$, as well as the payload $q$. The areas of the working reinforcement $A_{s 1}, A_{s 2}$, the section width $b_{f}$, as well as the classes of concrete and reinforcement are subject to independent variation. The arrangement scheme and the area of transverse reinforcement (Fig. 3, d) are considered constant. The cost of transverse reinforcement and reinforcement of the compressed zone of concrete, as well as the cost of manufacturing the frame, are taken into account when calculating the structure in the form of a constant value of 1800 rubles. The set of variable parameters admissible for selection in table 1 is formulated.

Table 1. Sets of independently variable parameters

\begin{tabular}{|l|l|}
\hline \multicolumn{1}{|c|}{ Parameter } & \multicolumn{1}{|c|}{ Values } \\
\hline Rebar section area $A_{s 1}$ & $\begin{array}{l}\text { 1) 4d16, 2) 3d16, 3) 2d16, 4) 4d14, 5) 3d14, 6) 2d14, } \\
\text { 7) 4d12, 8) 3d12, 9) 2d12, 10) 4d10, 11) 3d10, 12) 2d10 }\end{array}$ \\
\hline Rebar section area $A_{s 2}$ & $\begin{array}{l}\text { 1) 4d16, 2) 3d16, 3) 2d16, 4) 4d14, 5) 3d14, 6) 2d14, } \\
\text { 7) 4d12, 8) 3d12, 9) 2d12, 10) 4d10, 11) 3d10, 12) 2d10 }\end{array}$ \\
\hline Section width $b_{f}$ & 1) 200, 2) 220, 3) 240, 4) 260, 5)280, 6)300 \\
\hline Concrete class & 1) B15, 2) B20, 3) B25 4) B30 \\
\hline Reinforcements class & 1) A400, 2) A500 \\
\hline
\end{tabular}


The design requirements for the placement of rods across the section width are taken into account by assigning a minimum width of $200 \mathrm{~mm}$ with the possibility of placing 4d16. Distance between rods: $(200-50-48) / 3=34 \mathrm{~mm}>\mathrm{d}=16 \mathrm{~mm}$. The search for a solution was carried out based on a genetic algorithm when considering 10 variants of the design solution at each iteration. The scheme of grouping parameters was used, shown in fig. 4. Description of the problems of finding a solution for a different number of varied parameters is shown in table 2 .

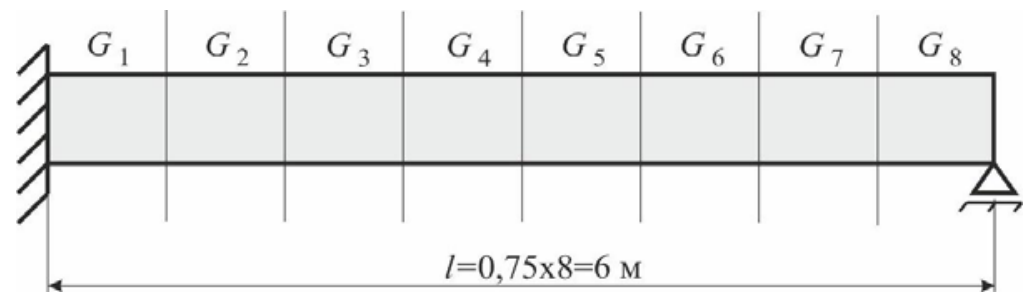

Fig. 4. Grouping of parameters for parts of a beam, used for different numbers of variable parameters

Table 2. The sets of independently variable parameters during normal operation of the structure

\begin{tabular}{|c|c|c|}
\hline No. & $\begin{array}{l}\text { Optimization } \\
\text { problem }\end{array}$ & Variable parameters \\
\hline 1 & 2 & 3 \\
\hline 1 & $C \mid N=1 \rightarrow \min$ & $\begin{array}{c}\text { rebar section area } A_{s 1}=A_{s 2} \text { along the entire } \\
\text { length of the beam }\end{array}$ \\
\hline 2 & $C \mid N=2 \rightarrow \min$ & $\begin{array}{l}\text { - rebar section area } A_{s 1} \text { for parts } G_{1}, G_{2} \\
\text { - rebar section area } A_{s 2} \text { for parts } G_{3}-G_{8}\end{array}$ \\
\hline 3 & $C \mid N=3 \rightarrow \min$ & $\begin{array}{l}\text { - rebar section area } A_{s 1} \text { for parts } G_{1}, G_{2} \\
\text { - rebar section area } A_{s 2} \text { for parts } G_{3}-G_{8} \\
\quad \text { - section width } b_{f} \text { for the entire span }\end{array}$ \\
\hline 4 & $C \mid N=4 \rightarrow \min$ & $\begin{array}{l}\text { - rebar section area } A_{s 1} \text { for parts } G_{1}, G_{2} \\
\text { - rebar section area } A_{s 2} \text { for parts } G_{4}-G_{6} ; \\
\text { - rebar section area } A_{s 2} \text { for parts } G_{3}, G_{7}, G_{8} \\
\text { - section width } b_{f} \text { for the entire span }\end{array}$ \\
\hline 5 & $C \mid N=5 \rightarrow \min$ & $\begin{array}{l}\text { - rebar section area } A_{s 1} \text { for part } G_{1} \\
\text { - rebar section area } A_{s 1} \text { for part } G_{2} \\
\text { - rebar section area } A_{s 2} \text { for parts } G_{4}-G_{6} \\
\text { - rebar section area } A_{s 2} \text { for parts } G_{3}, G_{7}, G_{8} \\
\text { - section width } b_{f} \text { for the entire span }\end{array}$ \\
\hline 6 & $C \mid N=6 \rightarrow \min$ & $\begin{array}{l}\text { - rebar section area } A_{s 1} \text { for parts } G_{1} \\
\text { - rebar section area } A_{s 1} \text { for part } G_{2} ; \\
\text { - rebar section area } A_{s 2} \text { for parts } G_{4}-G_{6} ; \\
\text { - rebar section area } A_{s 2} \text { for parts } G_{3}, G_{7}, G_{8} ; \\
\text { - section width } b_{f} \text { for the entire span; } \\
\text { - reinforcements class; }\end{array}$ \\
\hline
\end{tabular}


Continuation of table 2

\begin{tabular}{|c|c|c|}
\hline 1 & 2 & 3 \\
\hline 7 & $C \mid N=7 \rightarrow \min$ & - rebar section area $A_{s 1}$ for part $G_{1} ;$ \\
& & - rebar section area $A_{s 1}$ for part $G_{2} ;$ \\
& & - rebar section area $A_{s 2}$ for parts $G_{4}-G_{6} ;$ \\
& - rebar section area $A_{s 2}$ for parts $G_{3}, G_{7}, G_{8} ;$ \\
& & - section width $b_{f}$ for the entire span \\
& & - reinforcements class; - concrete class; \\
\hline
\end{tabular}

In problems No. 1, No. 2 (table 2), the beam section width is assumed constant and equal to $300 \mathrm{~mm}$. In all problems where the class of concrete and reinforcement did not vary, it was taken equal to B20 and A500. The search results for design solutions during normal operation are presented in table 3.

Table 3. The optimization results

\begin{tabular}{|c|c|c|}
\hline No. & $\begin{array}{l}\text { Optimization } \\
\text { problem }\end{array}$ & Value of variable parameter \\
\hline 1 & $C \mid N=1 \rightarrow \min$ & рабочая арматура $A_{s 1}, A_{s 2}: 4 \mathrm{~d} 16$ \\
\hline 2 & $C \mid N=2 \rightarrow \min$ & $\begin{array}{l}A_{s 1} \text { for parts } G_{1}, G_{2}: 4 \mathrm{~d} 16 ; A_{s 2} \text { for parts } \\
G_{3}-G_{8}: 4 \mathrm{~d} 12\end{array}$ \\
\hline 3 & $C \mid N=3 \rightarrow \min$ & $\begin{array}{l}A_{s 1} \text { for parts } G_{1}, G_{2} 4 \mathrm{~d} 16 ; A_{s 2} \text { for parts } \\
G_{3}-G_{8} 4 \mathrm{~d} 12 ; \text { section width } b_{f}: 200 \mathrm{~mm}\end{array}$ \\
\hline 4 & $C \mid N=4 \rightarrow \min$ & $\begin{array}{l}A_{s 1} \text { for parts } G_{1}, G_{2} 4 \mathrm{~d} 16 ; A_{s 2} \text { for parts } \\
G_{4}-G_{6} 4 \mathrm{~d} 12 ; A_{s 2} \text { for parts } G_{3}, G_{7}, G_{8} 4 \mathrm{~d} 10 \\
\text { section width } b_{f}: 220 \mathrm{~mm}\end{array}$ \\
\hline 5 & $C \mid N=5 \rightarrow \min$ & $\begin{array}{l}A_{s 1} \text { for parts } G_{1} 4 \mathrm{~d} 16 ; A_{s 1} \text { for part } G_{2} 2 \mathrm{~d} 16 ; \\
A_{s 2} \text { for parts } G_{4}-G_{6} 4 \mathrm{~d} 12 ; A_{s 2} \text { for parts } \\
G_{3}, G_{7}, G_{8} 4 \mathrm{~d} 10 ; \text { section width } b_{f}: 220 \mathrm{~mm}\end{array}$ \\
\hline 6 & $C \mid N=6 \rightarrow \min$ & $\begin{array}{l}A_{s 1} \text { for parts } G_{1} 4 \mathrm{~d} 16 ; A_{s 1} \text { for part } G_{2} 2 \mathrm{~d} 16 \text {; } \\
A_{s 2} \text { for parts } G_{4}-G_{6} 4 \mathrm{~d} 12 ; A_{s 2} \text { for parts } \\
G_{3}, G_{7}, G_{8} 4 \mathrm{~d} 10 ; \text { section width } b_{f} 220 \mathrm{~mm} \text {; } \\
\text { reinforcements class: A } 500 ;\end{array}$ \\
\hline 7 & $C \mid N=7 \rightarrow \min$ & $\begin{array}{l}A_{s 1} \text { for parts } G_{1} 4 \mathrm{~d} 16 ; A_{s 1} \text { for part } G_{2} 2 \mathrm{~d} 14 ; \\
A_{s 2} \text { for parts } G_{4}-G_{6} 2 \mathrm{~d} 16 ; A_{s 2} \text { for parts } \\
G_{3}, G_{7}, G_{8} 3 \mathrm{~d} 12 ; \text { section width } b_{f} 200 \mathrm{~mm} ; \\
\text { reinforcements class A } 500 ; \text { concrete class B25 }\end{array}$ \\
\hline
\end{tabular}

The calculation of the cost of structural solutions was carried out at the following costs concrete of class B20 - 3230 rubles $/ \mathrm{m}^{3}$, B30 - 3800 rubles $/ \mathrm{m}^{3}$, the cost of reinforcement A500 of all diameters is 38,000 rubles/ton. The dependence on costs obtained is illustrated in fig. 5.

Consider also the emergency actions, including the failure of the rotation constraint in the support embedment, which simulates the loss of flexural strength of the support section, wherein $A_{s 1}=0$. It is believed that when this connection is deactivated, a dynamic effect 
occurs, leading to an additional load with a coefficient of 1.75 . The beam section width is taken constant and equal to $400 \mathrm{~mm}$. In all the problems where the class of concrete and reinforcement did not vary, it was taken equal to B20 and A500. The deflection of the damaged structure is limited by the value $l / 30=6000 / 30=200 \mathrm{Mm}$. Transverse reinforcement is adopted with a diameter of $8 \mathrm{~mm}$. The cost of reinforcement A500 of all diameters is 38,000 rubles/ton, for reinforcement A400 - 35,500 rubles/ton. In addition, both during normal operation and during emergency, approximately, the cost of formwork has been factored in as a share of the concrete volume $C_{o p}=1000 \mathrm{rubles} / \mathrm{m}^{3}$. The results are presented as graphs of the dependence of the cost of the structure on the number of various parameters during normal operation and emergency actions (Fig. 5).

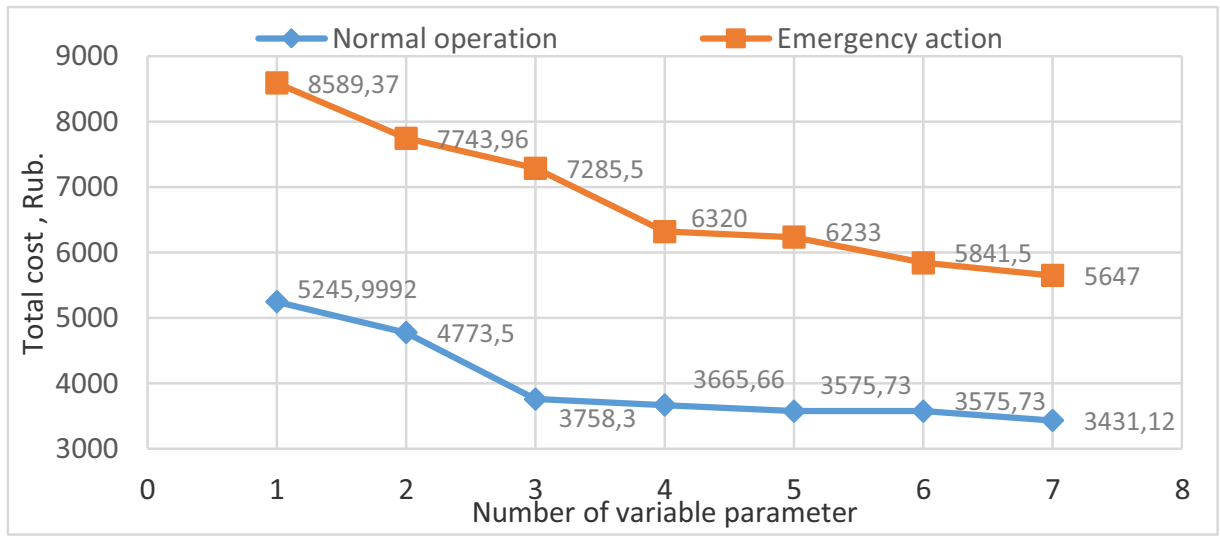

Fig. 5. Dependence of the optimal project cost on the number of variable parameters

Here the price includes the cost of concrete, longitudinal working reinforcement and formwork. The graph shows that for normal operation with varying five and six parameters, the cost is the same. This is because when introducing the sixth parameter, which is responsible for the class of concrete, the same class was chosen as when varying five parameters.

\section{Discussion}

An increase in the number of variable parameters when solving optimization problems inevitably leads to a deterioration in convergence to the optimal solution. However, the use of tools for increasing the performance of algorithms, such as a priori rejection of variants of objects [5], the use of combined methods of taking into account constraints, penalty functions allows solving problems with a sufficiently large number of variable parameters. Research of this thread for special tasks [21, 22] of designing reinforced concrete structures is relevant.

\section{Conclusion}

The analysis performed allows us to draw the following conclusions:

- with an increase in the number of variable parameters, the cost of the basic materials of the structural system decreases;

- the total cost of the structure with an increase in the number of variable parameters decreases to a certain minimum value corresponding to the minimum cost of basic materials, manufacturing technology, labor intensity of the device of nodal connections, 
auxiliary materials, etc. This value is usually achieved subject to the requirements for unification of the design solution.

\section{References}

1. V. Togan, A.T. Daloglu Computers and Structures 86 (2008) 1204-1218

2. Gibb, S., La, H.M., Louis, S. in (2018) 2018 IEEE Congr. Evol. Comput. CEC 2018 Proc., . doi:10.1109/CEC.2018.84777909445(2003) 129:1(105)

3. Zhang, G., Ali, Z.H., Aldlemy, M.S., Mussa, M.H., Salih, S.Q., Hameed, M.M., AlKhafaji, Z.S., Yaseen, Z.M. Engineering with Computers. doi:10.1007/s00366-02001137-1 (2020).

4. Mangal, M., Cheng, J.C.P. Automation in Construction. doi:10.1016/j.autcon.2018.01.01302380-x (2018)

5. Alekseytsev, A., Botagovsky, M., Kurchenko, N. E3S Web of Conferences, 2019, 97, 03002

6. Prokurov, M., Indykin, A., Alekseytsev, A. MATEC Web of Conferences, 2018, 251, 04017

7. Assimi, H., Jamali, A., Nariman-zadeh, N. 2017. Swarm and Evolutionary Computation. 37 pp. 90-103. doi:10.1016/j.swevo.2017.05.009

8. Camp, C. V., Pezeshk, S., Hansson, H. Flexural 2003. Journal of Structural Engineering. doi: $10.1061 /($ asce $) 0733$

9. Kirsanov, M., Serdjuks, D., Buka-Vaivade, K. Lecture Notes in Civil Engineering 70, p. 25-35 (2020)

10. Alekseytsev, A.V., Al Ali, M. Magazine of Civil Engineering, 2018, 83(7), стр. 175185

11. Tamrazyan, A., Alekseytsev, A. E3S Web of Conferences, 2019, 97, 04005

12. Zinkova, V.A. Lecture Notes in Civil Engineering, 2021, 95, стр. 213-218

13. Tamrazyan, A., Alekseytsev, A. IOP Conference Series: Materials Science and Engineering, 2020, 869(5), 052027

14. Lushnikova, V.Y., Tamrazyan, A.G. Magazine of Civil Engineering, 2018, 80(4), стр. 128-137

15. Kirsanov, M.N. $\quad 2020 \quad$ Magazine of Civil Engineering 96(4), c. 110-117

16. Tamrazyan, A.G. IOP Conference Series: Materials Science and Engineering, 2018, 365(5), 052021

17. Klyuev, S.V., Shlychkov, D.I., Muravyov, K.A., Ksenofontova, T.K. 2020 International Journal of Advanced Science and Technology 29(5), c. 2577-2583

18. A.V. Alekseytsev, S.A. Akhremenko, Magazine of Civil Engineering 5 (81), 32-42 (2018)

19. Loganina, V., Fediuk, R., Vatin, N. 2020 IOP Conference Series: Materials Science and Engineering 896(1), 012001

20. Tamrazyan, A., Alekseytsev, A. IOP Conference Series: Materials Science and Engineering, 2020, 869(5), 052019

21. Tamrazyan, A.G., Avetisyan, L.A. IOP Conference Series: Materials Science and Engineering, 2018, 365(5), 052034

22. Tamrazyan, A., Avetisyan, L. Applied Mechanics and Materials, 2014, 638-640, стр. 62-65

23. Fan, Z., Xia, L., Lai, W., Xia, Q., Shi, T. 2019. Structural and Multidisciplinary Optimization. 59 (2), pp. 647-658. doi:10.1007/s00158-018-2090-4

24. Serpik, I., Alekseytsev, A. IOP Conference Series: Materials Science and Engineering, 2018, 365(5), 052003 